\title{
O ser humano como ser de relações
}

Flávio José de Paula ${ }^{1}$

A pergunta sobre o que é o ser humano é eterna e caracteriza o próprio ser humano enquanto "ser em busca", mas por outro lado recebe respostas historicamente situadas. Isso significa que o ser humano pode ser compreendido, em primeiro lugar, como um ser que, desde que se reconhece como tal, pergunta-se a si mesmo o que ele é. As respostas a essa pergunta, no entanto, foram elaboradas e reelaboradas de diversas maneiras através dos tempos e apresentadas sob as mais diversas perspectivas. O cristianismo, ao longo de sua história, buscará uma resposta que articule e integre certos dados essenciais da fé, como a concepção do ser humano como pessoa ou ainda como "ser de relação", com todas as implicações desses conceitos.

A concepção de pessoa é um conceito, originado em contexto cristão, que indica a situação única do ser humano em relação às outras criaturas. A relação com Deus, vista como fundamento para as relações com os demais seres humanos e com a criação, é a perspectiva em torno da qual o cristianismo desenvolveu esse conceito. Assim, à concepção clássica de pessoa como única, irrepetível e insubstituível, inerentes ao próprio conceito, soma-se a ideia central de relacionalidade.

Além dessas características, devemos perceber que a pessoa, pela dimensão de imanência, ou seja, pela dimensão que a coloca em relação consigo mesma, é chamada a ser dona de si mesma (autopossessão), a ser livre e responsável (autorresponsabilidade) e a ser dotada de finalidade própria, isto é, a perceber que cada pessoa humana tem valor em si mesma (autofinalidade), não sendo, portanto, destinada a um fim que não seja o fato de ser ela mesma.

A autopossessão é o chamado que o ser humano tem para assumir que pertence a si mesmo enquanto ser; de fato, essa concepção demonstra como o ser humano deve ser senhor de si - e com isso nega-se, obviamente, qualquer tipo de escravidão ou senhorio de um homem sobre o outro. Por outro lado, pelo termo autorresponsabilidade destacam-se a liberdade e a responsabilidade inerentes ao ser humano; em outras palavras, é inerente à própria humanidade o fato de se poder decidir livremente, bem como a necessidade de se assumir as responsabilidades que forem consequências dessas decisões. Outra especificidade da dimensão de imanência é a autofinalidade, que indica o valor que o ser humano tem pelo simples fato de o ser (perseidade/inseidade) - e com isso, nega-se que o ser humano tenha uma utilidade, ou que exista para uma finalidade diferente daquela de simplesmente existir para si e por si.

\footnotetext{
${ }^{1}$ Aluno de Graduação em Teologia 2017.1.
} 
No entanto, a autopossessão, a autorresponsabilidade e a autofinalidade, que indicam a relação da pessoa consigo mesma, não esgotam o ser humano; antes, elas acontecem na relação, de maneira que o ser humano não fique fechado em si mesmo. Como cada pessoa não é um ser abstrato, mas um sujeito concreto na história, a maneira de se realizar o ser humano enquanto ser humano só se dá através da relacionalidade nos diferentes contextos. Percebendo-se, então, o não fechamento do ser humano em sua dimensão de imanência, podemos afirmar que cada pessoa tem uma dimensão de abertura ao diferente de si que lhe é constitutiva e que não lhe pode ser negada: a dimensão de transcendência.

Portanto, além de sua dimensão de imanência, há também essa abertura constitutiva do ser humano, que é exatamente a sua dimensão relacional, ou transcendente. Essas relações do homem que se abre se dão, além desse relacionamento consigo mesmo, em três diferentes níveis, a saber: o relacionamento com o mundo, com outros e com Deus.

Pela abertura ao mundo, embora perceba-se qualitativamente diferente do restante da natureza, a pessoa humana descobre-se como criatura entre as criaturas - o que a coloca no nível da relacionalidade com tudo à sua volta. $O$ fato de perceber o mundo à sua volta e não se confundir com ele faz com que a humanidade entre em relação com esse outro. Um problema que pode destruir essa relação é o domínio sobre a natureza, especialmente quando se desrespeita os limites desta. De fato, o homem deve perceber-se em uma relação recíproca com o mundo, na qual reconhece e aceita que não pode se fazer qualquer coisa com aquilo que é diferente dele.

Pela abertura aos outros, o ser humano vê-se como um ser de relação com aqueles iguais a si mesmo - o que comporta necessariamente uma abertura para a dimensão sóciopolítica, fundamental no próprio ser humano, pois nasce da relação "eu-tu". De fato, o sair de si para o encontro do outro é constitutivo da pessoa. Nesse caso, as dimensões de liberdade, autonomia e autofinalidade, presentes em cada pessoa em sua dimensão de imanência, têm de ser articuladas com essa dimensão de abertura fundamental. Sendo assim, a relacionalidade é o chamado que o ser humano tem para articular-se com os outros tendo em vista a realização de si mesmo. Portanto, a alteridade, como reconhecimento do outro enquanto outro, é um meio de humanizar-se; e o rompimento das relações em qualquer nível, ao contrário, é aquilo que desumaniza a pessoa.

Através da abertura a Deus, o ser humano pode perceber-se como um ser de resposta, pois é essa relação que faz de cada ser humano não apenas um indivíduo da espécie humana, mas uma pessoa aberta a realizar-se plenamente. Esse chamado a relacionar-se com Deus, que Ihe apresenta uma proposta, e consequentemente um convite ao diálogo, coloca o ser humano como um ser de acolhimento, resposta e relação. Essa 
dimensão de abertura a Deus leva à plenitude o conceito de ser humano como um "ser de relações", e, portanto, de abertura e de diálogo com o diferente.

Uma vez compreendido os aspectos essenciais do ser humano, urge a vontade de se saber se é possível o ser humano desumanizar-se. De fato, todas as vezes que a pessoa humana se encontrar em uma posição na qual as suas características básicas forem suprimidas, a saber, a negação das dimensões de sua relacionalidade, a pessoa estará sendo desumanizada, isto é, estará se dando o oposto do que é próprio ao ser humano.

Ao negar o caráter relacional da pessoa humana, isto é, os seus diversos níveis de relação (seja imanente - consigo mesmo -, seja transcendente - com o mundo, com os outros e com Deus), o ser humano coloca-se acima de tudo, numa espécie de autoidolatria, dominando a natureza, escravizando homens e, consequentemente, negando a divindade. Nessa situação, o ser humano, negando as relações constitutivas do seu próprio ser, desumaniza-se.

O primeiro aspecto de desumanização é o rompimento da alteridade. As relações entre as pessoas comportam o reconhecimento do outro enquanto outro, de maneira que, toda vez que ao outro for negado a sua alteridade, negar-se-á também sua humanidade. As relações devem ser estabelecidas dentro de uma dinâmica de articulação-integração que respeite o outro como um todo, e com todos os seus aspectos fundamentais. Por isso mesmo, a afirmação excessiva de uma dimensão de uma pessoa que chegue a negar essa mesma dimensão a outra pessoa é desumanizante. De fato, a liberdade de um homem não pode ser afirmada em detrimento da liberdade de outrem. Nesse caso, tanto quem escraviza quanto aquele que é escravizado têm a sua humanidade posta em xeque.

O caráter de pessoa, próprio do ser humano, quando negado em suas características é outro fator de desumanização. Assim, deve ser respeitada a unicidade de cada pessoa - e com isso a sua irrepetibilidade e insubstituibilidade. Devem ser preservadas também a autopossessão, a autorresponsabilidade e a autofinalidade de cada pessoa como maneiras de se resguardar a dignidade que Ihe é própria. Assim também, a liberdade humana não pode ser restringida nem manipulada. A abertura transcendente que o ser humano tem para a relação com as criaturas, para com os outros humanos e para com Deus também não pode ser negada a cada ser individual.

A humanização do ser humano é, ao contrário, em primeiro lugar, o reconhecimento de que ele é "chamado a ser ele mesmo em suas relações", reconhecendo a alteridade, na qual se estabelece uma relação com o outro numa dinâmica de integração. Em outras palavras, a humanização é um processo de realização das nossas relações fundamentais.

Assim, as diversas situações que impedem o ser humano de realizar sua dimensão imanente, ou seja, a sua a plena autonomia ou independência na relação consigo mesmo como a submissão a estruturas sócio-políticas na qual se nega a liberdade e a 
responsabilidade humanas - são desumanizadoras. Como exemplo dessa desumanização, pode-se falar da escravidão, na qual a liberdade é negada. Além disso, nesse exemplo, há uma instrumentalização do ser humano que Ihe nega a sua condição de autofinalidade - ou seja, nega-se o fato de que cada pessoa tenha uma finalidade em si mesma. Na escravidão, ao contrário, a pessoa é colocada em função de outra, utilizada como um mero objeto funcional.

Além disso, entendendo que no ser humano há também uma dimensão de transcendência, toda vez que essa lhe for negada, a desumanização também se faz presente. Aliás, o ser humano é chamado a ser ele mesmo nas relações, e por isso mesmo, a não realização dessa expectativa fundamental humana nega também a própria humanidade. Assim, na realização das relações com o outro, com o mundo ou com Deus, o homem realiza-se a si mesmo. Ao contrário, quando se nega algumas dessas dimensões, o processo de desumanização avança. Por isso, deve-se perceber a importância de um bom relacionamento com o ecossistema, no nível pessoal e global, como fonte de humanização. Também os encontros no nível eu-tu, ou ainda no nível da dimensão sócio-política são pilares constitutivos do ser humano. Sem eles, o homem nega-se a si mesmo. Por fim, a abertura a Deus, como uma radicalização da dimensão transcendente do homem, humaniza-o, pois realiza-se plenamente o seu próprio chamado de ser um "ser de relações".

\section{Bibliografia:}

RUBIO, Alfonso García. Unidade na Pluralidade: O ser humano à luz da fé e da reflexão cristãs. $3^{a}$ ed. rev. e ampl. São Paulo: Paulus, 2001. Coleção Teologia Sistemática.

\section{Para refletir:}

1. Como podemos compreender as dimensões de imanência e de transcendência no ser humano? O que as caracteriza e como se relacionam?

2. O que acontece com o ser humano quando umas dessa duas dimensões não é considerada ou é colocada em segundo plano? 